\title{
GOLD TREATMENT IN RHEUMATOID ARTHRITIS
}

\author{
BY \\ THOMAS N. FRASER \\ Glasgow
}

This investigation was undertaken for the Empire Rheumatism Council as part of a wider scheme to assess the value of gold salts in the treatment of rheumatoid arthritis. It was originally planned that the work should be carried out at various centres throughout the country, but unfortunately the war intervened and the main scheme had to be abandoned. It was found possible, however, to carry on with the experiment on a smaller scale at the Gardiner Institute of Medicine. The investigation was concentrated on classical cases of rheumatoid arthritis in which clinical activity was known to have been present for two to five years. In addition, women should have shown the first signs of the disease before the age of 40 and men before the age of 50 . The period of observation extended over one year.

Gold therapy has been in use for a number of years, and, on the whole, the published results have been favourable. It should be pointed out, however, that in few instances has any attempt been made to control these observations, especially the psychological aspects of the treatment, in large clinics. One of the chief aims in this investigation was to neutralize the psychological effect usually associated with "having an injection." With this in view the patients were divided roughly into two equal groups, one receiving injections of myocrisin and the other an inactive control substance, identical in appearance with the gold salt and provided by the makers in similar phials. It was not made known to me which patients had received the former and which the latter until after I had completed and recorded my final observations. In this way an attempt was made to control the investigation adequately, and the results are embodied in this paper.

\section{Historical}

In 1890 Koch stated that gold cyanide in dilutions of $1: 2,000,000$ inhibited the in vitro growth of the tubercle bacillus; since then many therapeutic trials have been carried out with gold salts. Junker (1913) gave gold cyanide intravenously to eleven patients with pulmonary tuberculosis, and stated that his general impression of the results was not unfavourable. Feldt (1917) introduced a complex organic compound of gold-krysolgan-which he used in experimental animal infections with tuber- culosis. It was not until 1924, however, that gold salts became recognized as a useful therapeutic agent, when Möllgaard used sanocrysin in the treatment of pulmonary tuberculosis and reported favourable results.

After the encouraging reports of the use of sanocrysin in tuberculosis, its effect was tried in other conditions. In 1926 Feldt introduced another new gold compound-solganal-which was used by Lewy and Freund (1926) with good results in streptococcal infections in man. Schmidt (1944) claimed that nearly twenty years ago he was among the first to employ gold in the treatment of the various types of arthritis and found that it had a very limited usefulness. In Stockholm, Hedenius (1926) reported good results with the use of colloidal gold in septic polyarthritis, and Landé (1927) was favourably impressed with solganal in the treatment of chronic polyarthritis. Pick (1927), however, using triphal, found little or no improvement in his small series of patients. The use of gold salts in rheumatoid arthritis spread rapidly throughout Europe, and almost simultaneously Forestier (1929) in France, and Umber (1929), Zimmer (1930), and Feldt (1930) in Germany published independent results of chrysotherapy in this disease. Forestier stated that his attention was drawn to the use of gold salts in the treatment of some of the forms of chronic arthritis by the analogy of the clinical evolution of certain severe types of chronic rheumatism with that of tuberculosis; he (Forestier, 1935) reported that $70-80 \%$ of over 550 patients responded favourably to gold therapy.

In this country reports on the treatment of rheumatoid arthritis with gold salts began to appear in 1934. Slot and Deville (1934) and Buckley (1934) used gold salts in two small series of cases with promising results. The latter felt that there was no greater risk with gold salts than with protein shock. The following year Pemberton (1935) published encouraging results in a series of 100 patients with varying types of chronic arthritis, and concluded that the response to gold salts was roughly inversely proportional to the duration of the disease. In subsequent years an increasing number of publications on this subject made their appearance. Crosby (1936), Bach (1936), Crawford (1937), Copeman and Tegner (1937), Hartfall et al. (1937), and Ellman et al. (1940) made valuable contributions to 
the literature. The most outstanding of these were the results of Hartfall and his co-workers at Leeds, who claimed that $80 \%$ of 750 patients with rheumatoid arthritis showed apparent cure or striking improvement.

In America gold therapy was not looked on with any great favour for a number of years. Philips (1936) used gold salts in 9 cases, but gave it up as he felt that, on account of its toxicity, he was " not competent to handle the drug to the advantage of the patient." In the same year, however, Oren (1936) found that $91 \%$ of 66 patients were improved. In more recent years many contributions on the subject have appeared, including favourable reports by Key et al. (1939), Snyder et al. (1939), Sashin et al. (1939), Dawson et al. (1941), and Cecil et al. (1942). Snyder and his associates felt that they obtained better results in older patients, a view that is at variance with other reports. Cecil and his colleagues found that relapses, usually milder than the original attack, were quite common in their series of 245 cases. Other work on gold therapy has been done by Secher aud Gudiksen (1935), Parr and Shipton (1937), Sundelin (1941), and Graham and Fletcher (1943). Sundelin, in an excellent monograph from Scandinavia, gives a detailed account of the literature on gold therapy, and reports the results of 730 cases of chronic inflammatory arthritis treated with a variety of gold preparations, some of the patients receiving as many as five courses of injections. He is very cautious in assessing his results, but he felt that $93 \%$ of the patients showed improvement although it was marked in less than half of these.

To sum up, the majority of observers have been favourably impressed with the use of gold salts in rheumatoid arthritis, and most have found that $70-80 \%$ of their patients respond well to this treatment.

\section{Clinical Material}

Age and Sex.-Of the 110 patients falling into the category described, 28 were males and 82 females -a ratio of approximately $1: 3$. Table 1 shows the patients in different age-groups at the onset of arthritis, but it should be remembered that no women over the age of 39 were included. It will be seen that more than half of the patients in this series fall into the age-group 30-39.

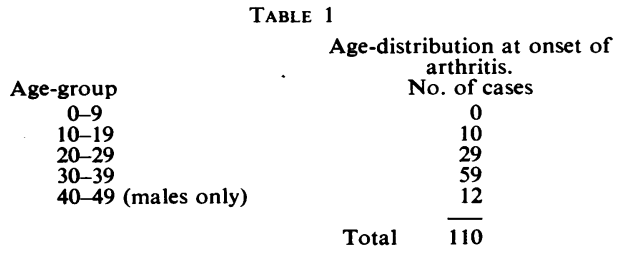

Previous Health.-Forty-nine of the patients had a history of rheumatic fever, scarlet fever, or tonsillitis. Of these, 11 were known to have had rheumatic fever. Three patients were suffering from psoriasis, and this had been present before the onset of the arthritis.
Family History.-Fifty-eight $(53 \%)$ of the patients stated that there was some form of "rheumatism" in the family, and, of these, $28(25 \%)$ had blood relations with rheumatoid arthritis.

Joint Involvement.-Bilateral and symmetrical involvement of the finger-joints was present in all the patients in the series.

Cardiac Involvement.-Valvular disease of the heart was present in $15(14 \%)$ of the patients, and high blood-pressure in 2.

Previous Treatment.-The majority of the patients had already had some form of treatment-e.g. eradication of septic foci, protein shock, salicylates, physiotherapy-with little or no improvement. None had been treated with gold salts.

\section{Method of Treatment}

All the patients, with one exception, had ambulatory treatment, and attended the clinic once a week for observation and injections. In addition, all received some form of physiotherapy, such as heat and massage. Before treatment was begun each patient was given a thorough clinical examination, including joint measurements, full blood count, blood sedimentation rate, blood uric acid, urine analysis, urea clearance, and radiological examination; the findings were charted on special case sheets. The same procedure was adopted at the end of the period of observation-i.e. one yearwhile during treatment weekly urine analysis, fortnightly white-blood-cell counts, and monthly blood sedimentation tests were carried out. A careful watch was kept for the first signs of intolerance to gold.

As already mentioned, roughly half the patients received myocrisin, an aqueous solution of gold sodium thiomalate containing $50 \%$ metallic gold; and half an inactive control substance. The latter contained the same constituents as the myocrisin with the exception of the gold radical, had the same appearance, and was made up in identical ampoules. As previously stated, it was not made known to me which patients had received myocrisin and which the inactive control substance until after I had completed and recorded my final observations on the progress of the disease. Both the myocrisin and the control substance were administered in the same way. Intramuscular injections were given into the buttocks at weekly intervals in the following doses: $1 \times 0.01,2 \times 0.02,1 \times 0.05$, and $9 \times 0.1 \mathrm{~g}$., giving a total of $1.0 \mathrm{~g}$. in a course. If necessary, after an interval of three months a second course of $1.0 \mathrm{~g}$. was given in the same dosage. As the period of observation was for one year only, it was not possible to give more than two courses of injections. Treatment was suspended temporarily when the milder forms of toxicity appeared, and permanently when the reactions were severe.

\section{Results of Treatment}

Of the 110 patients 61 had injections of myocrisin and 49 the inactive control substance. Owing to toxic reactions or to the patient's defaulting, 4 政

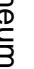 .


of the former and 3 of the latter are not included in the results of treatment. Thirteen of the patients on myocrisin and 28 on the control received two courses of injections, while the remainder received only one or part of one course.

It is difficult to decide what criteria to use in assessing the results of treatment. I have based the classification on my general impression of the progress made and on the change in the clinical signs - e.g. general condition, gain in weight, joint swelling, restoration of function, blood sedimentation rate, etc. The patients were divided arbitrarily into five groups : great, moderate, slight, and no improvement, and worse. No cures were claimed, as it is apparent that the patients were not observed over a sufficient period of time. The results of myocrisin are shown in Table 2 and of the inactive control substance in Table 3; the figures in parentheses in both representing the results as obtained from questioning the patient about his own opinion as to progress during the year.

TABLE 2

RESULTS OF TREATMENT WITH MYOCRISIN

\begin{tabular}{|c|c|c|c|c|c|}
\hline \multicolumn{4}{|c|}{ Result } & \multicolumn{2}{|c|}{ Cases } \\
\hline & & & & Number & $\%$ \\
\hline $\begin{array}{l}\text { Great imp. . } \\
\text { Moderate imp. } \\
\text { Slight imp. .. } \\
\text { No imp. } \quad \ldots \\
\text { Worse. } \quad .\end{array}$ & $\begin{array}{l}\cdots \\
\cdots \\
\because \\
\cdots\end{array}$ & $\begin{array}{l}\cdots \\
\cdots \\
\cdots \\
\cdots\end{array}$ & $\begin{array}{l}\cdots \\
\cdots \\
\cdots \\
\cdots\end{array}$ & $\begin{array}{l}24(32) \\
12(8) \\
11(6) \\
5(9) \\
5(2)\end{array}$ & $\begin{array}{l}42(56) \\
21(14) \\
19(11) \\
9(16) \\
9(3)\end{array}$ \\
\hline Total & . & . & . & 57 & 100 \\
\hline
\end{tabular}

TABLE 3

RESULTS OF TREATMENT WITH INACTIVE CONTROL SUBSTANCE

\begin{tabular}{|c|c|c|c|c|c|}
\hline \multicolumn{4}{|c|}{ Result } & \multicolumn{2}{|c|}{ Cases } \\
\hline & & & & Number & $\%$ \\
\hline $\begin{array}{l}\text { Great imp. . } \\
\text { Moderate imp. } \\
\text { Slight imp. . } \\
\text { No imp. } \quad \ldots \\
\text { Worse. } \quad . \\
\\
\\
\\
\end{array}$ & $\begin{array}{l}\cdots \\
\cdots \\
\cdots \\
\cdots \\
\cdots\end{array}$ & $\begin{array}{l}\cdots \\
\cdots \\
\cdots \\
\cdots \\
\cdots\end{array}$ & $\begin{array}{l}\cdots \\
\cdots \\
\cdots \\
\cdots \\
\cdots\end{array}$ & $\begin{array}{l}4(15) \\
6(12) \\
11(6) \\
10(6) \\
15(7) \\
\frac{1}{46}\end{array}$ & $\begin{array}{l}8(33) \\
13(26) \\
24(13) \\
22(13) \\
33(15) \\
\frac{100}{100}\end{array}$ \\
\hline
\end{tabular}

From these figures it will be seen that, while $82 \%$ of the patients who received myocrisin improved clinically, $45 \%$ of those on the control also showed some improvement. However, a closer study of the results shows that there is a considerable difference in the degree of improvement in the two groups. It is of interest to note that $72 \%$ of the control group felt that they had received some benefit from the injections, although only $45 \%$ showed clinical improvement.

Graham and Fletcher (1943) pointed out that a good result following on gold therapy was related to a fall in the blood sedimentation rate-the better the clinical result, the greater the fall. An analysis of the clinical results in relation to the sedimentation rate in both groups in this series is shown in Table 4.
TABLE 4

RELATION OF IMPROVEMENT TO FALL IN BLOOU SEDIMENTATION RATE

\begin{tabular}{|c|c|c|c|c|c|}
\hline \multirow{3}{*}{ Result } & & \multicolumn{4}{|c|}{ Sedimentation rate } \\
\hline & & \multicolumn{2}{|c|}{ Myocrisin } & \multicolumn{2}{|c|}{ Control } \\
\hline & & $\begin{array}{c}\text { Average } \\
\text { initial }\end{array}$ & $\begin{array}{l}\text { Average } \\
\text { final }\end{array}$ & $\begin{array}{c}\text { Average } \\
\text { initial }\end{array}$ & $\begin{array}{c}\text { Averiıge } \\
\text { final }\end{array}$ \\
\hline $\begin{array}{l}\text { Great imp... } \\
\text { Moderate imp. } \\
\text { Slight imp... } \\
\text { No imp. . . } \\
\text { Worse. .. }\end{array}$ & $\begin{array}{l}\ldots \\
\cdots \\
\cdots \\
\cdots\end{array}$ & $\begin{array}{l}23 \\
20 \\
26 \\
10 \\
15\end{array}$ & $\begin{array}{r}7 \\
9 \\
13 \\
9 \\
7\end{array}$ & $\begin{array}{l}47 \\
27 \\
11 \\
22 \\
19\end{array}$ & $\begin{array}{l}11 \\
17 \\
14 \\
17 \\
31\end{array}$ \\
\hline
\end{tabular}

Of the 57 patients who received myocrisin 19 were unable to continue with their work when first seen, while of the 46 patients on the control substance 14 were similarly incapacitated. By the end of the period of observation 17 of the former and 4 of the latter had been able to resume their employment.

Blood uric acid estimations (Benedict, 1922) were carried out before and after treatment in all the patients in this series. Out of the 110 patients 12 had initial levels above the normal $(2-4 \mathrm{mg} . / 100 \mathrm{c.cm}$.), the highest being $6.0 \mathrm{mg}$. Of these, 7 received myocrisin and 5 the inactive control substance. The final levels were within normal limits in 11 of the 12 cases, and in the twelfth the blood uric acid fell from $6.0 \mathrm{mg}$. to $4.4 \mathrm{mg}$. after one course of myocrisin.

\section{Toxic Reactions}

It is a well recognized fact that the use of gold salts in the treatment of rheumatoid arthritis is not without its dangers. The incidence of toxic reactions is high, according to many observers appearing in about half the cases. The majority of reactions are of a mild nature, but fatalities have been recorded from time to time (Forestier, 1935, Ellman and Lawrence, 1935; Hartfall and Garland, 1935 and 1936). These were usually associated with the larger dosages that were given in the earlier days of gold therapy. In the present series $75 \%$ of the 61 patients who received gold injections developed toxic manifestations (Table 5) - a figure higher than that generally reported-but the majority of these were mild. Seven patients had multiple reactions. Most of the reactions occurred during the first course of injections, but some appeared in the second course, and a few were delayed, making their appearance some time after the cessation of treatment. It is of interest to note that $37 \%$ of the 49 patients who were given the control substance had "toxic reactions" (Table 6).

TABLE 5

TOXIC REACTIONS FOLLOWING THE USE OF MYOCRISIN IN 61 CASES OF R.A.

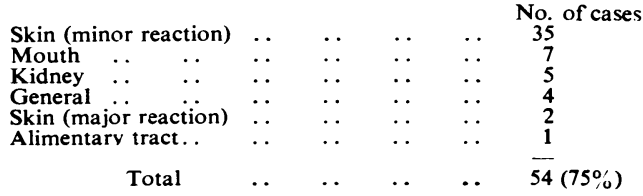


TABLE 6

“ TOXIC REACTIONS" FOLLOWING THE USE OF AN INACTIVE CONTROL SUBSTANCE IN 49 CASES OF R.A.

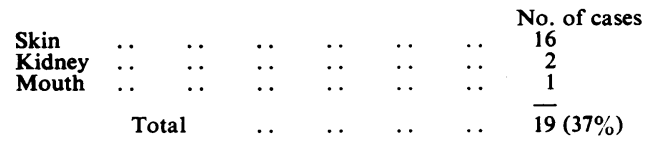

General Reactions.-These were noted in 4 of the patients who received myocrisin, and consisted of headache and shivering immediately after each injection.

Skin Reactions.-These appeared in 37 of the 61 patients who received myocrisin injections, but only 2 were of a severe nature and gave rise to some anxiety. Both of these patients were admitted to hospital for a period of six weeks, but it was several months before the skin had returned to its normal condition. The remaining 35 patients had reactions of a minor character, 7 of them having pruritus only. Other skin lesions were simple erythema, macular, maculo-papular, papular, pustular, squamous, and exudative dermatitis. Some of these were accompanied by fissuring of the palms of the hands, and others by desquamation of the skin. Treatment was discontinued only temporarily in most of these cases. There were several cases of delayed reactions; in one instance a patchy exudative dermatitis appeared three months after the cessation of gold therapy. Sixteen of the 49 patients who received the inactive control substance complained of skin lesions. Of these, 10 had pruritus only; 2 a papular dermatitis; and the other 4 an erythema, a pustular rash, a seborrhoeic dermatitis, and a dermatitis infectiosa respectively. It should be pointed out that all the patients were made "skin conscious" before treatment started, and were instructed to report anything out of the usual.

Mouth Lesions.-These were noticed in 7 patients who had myocrisin injections. Four of these had ulceration of the lips, cheeks, and gums, and 3 complained of soreness of the mouth without any lesions. One of the patients on the control substance stated that she had a metallic taste in her mouth during treatment.

Kidney.-A mild transient albuminuria appeared in about half of the patients in both the myocrisin and the control groups, but was not considered of sufficient importance to be included in the kidney reactions. Only 5 of the patients who received myocrisin showed any definite evidence of kidney damage. Albumin, red blood cells and casts were found in the urine and treatment was abandoned. Two of the control patients also developed albumin and casts in the urine. The urea clearance test (McIntosh et al., 1928) was performed on all the patients in both groups in this series before and after each course of injections, but the results did not show anything of significance even in those cases in which blood and casts were found in the urine.

Alimentary Tract.-One patient developed a colitis with blood and mucus in the stools after receiving $0.6 \mathrm{~g}$. of myocrisin. This proved very resistant to treatment, and, when seen recently,
17 months after the onset, the patient stated that although the condition was much better he still had periodic attacks of diarrhœa without blood or mucus.

Blood.-A decrease in the white cell count was noticed during treatment in the majority of patients receiving myocrisin, but in no instance did it fall below 3,000 per c.mm. The count returned to its original level shortly after the end of treatment. It was noticeable that the haemoglobin generally rose in those patients who responded to gold therapy.

It has been the experience of most observers that those patients who develop toxic reactions generally have a marked alleviation of the joint condition. This was found to be true in the present series, especially with the more severe reactionse.g. exfoliative dermatitis and colitis.

\section{Discussion}

Although the number of patients in this series is small and the period of observation for the purposes of the investigation-i.e. one year-is short, it is justifiable to draw certain conclusions. It should be borne in mind, however, that treatment was confined to one small group of patients suffering from rheumatoid arthritis. In the first instance the patients had had the condition for $2-5$ years. This choice was made in an attempt to eliminate so far as possible the inclusion of patients showing spontaneous remissions, which are most common during the first two years of the disease, and to exclude old-standing cases in which the disease might have burned itself out. Secondly, men should have shown the first signs of the disease before the age of 50, and women before the age of 40 . In this way it was thought to avoid any complicating factor associated with the menopause. Thirdly, every patient had some form of physiotherapy, such as heat and massage. Lastly, I wish to stress again one important point-namely, that I was completely unaware of what each patient was receiving during his course of injections.

Of the 57 patients who received myocrisin $82 \%$ showed clinical signs of improvement compared with $45 \%$ of the 46 patients on the control substance. At first sight these figures do not seem $\sigma$ very encouraging, as there is only a $37 \%$ difference $N$ in favour of the myocrisin; but on going into the $\underset{\mathrm{N}}{ }$ results more closely (Tables 2 and 3 ) it is found that, whereas $42 \%$ of the former showed great improvement, only $8 \%$ of the latter improved to this extent. Similarly, $21 \%$ of these on myocrisin were moderately $\stackrel{?}{?}$ improved as against $13 \%$ of the controls. Slight improvement was noted in $19 \%$ of the myocrisin

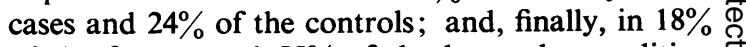
of the former and $55 \%$ of the latter the condition $\stackrel{\otimes}{\otimes}$ remained stationary or deteriorated.

Why should the control patients have shown any improvement? The explanation probably lies in $\frac{8}{0}$ the fact that all the patients received some form of physiotherapy, and, secondly, that spontaneous re- $\frac{\hat{\partial}}{\partial}$ mission must have occurred in a number of cases. In the same way it would be reasonable to suggest 
that these two factors were responsible for the improvement shown in roughly the same percentage of cases in the myocrisin group. If this were so, the figures showing improvement as the result of gold therapy would be appreciably reduced-viz., to $34 \%$ great improvement and $8 \%$ moderate improvement. It should be explained, however, that only 13 of the 57 patients had more than one course of gold injections, and that, while the condition of many of those receiving only one course improved considerably during the treatment, it had regressed by the end of the period of observation. It was unfortunate that war work prevented many from attending for further therapy.

I have already drawn attention to the fact that $72 \%$ of the patients who received the inactive control substance improved subjectively, although only $45 \%$ showed objective (clinical) improvement. This finding suggests that a psychological factor is present and must be borne in mind, more particularly when the patient's statements as to progress are used as one of the criteria in assessing results.

From my results it is fair to assume that the good results claimed for gold therapy in rheumatoid arthritis by the majority of observers are unjustifiably high owing to lack of adequate controls. Likewise, the same criticism will apply to other forms of treatment in this condition, and, indeed, in all diseases. Great caution should therefore be observed in assessing the results of any form of therapy, and extravagant claims for any new drug should be avoided unless the investigation has been properly controlled.

In conclusion, in my view gold therapy is the best single form of treatment in rheumatoid arthritis that we have at our disposal at the present time, and that its results are enhanced when used in conjunction with general, physiotherapeutic and orthopaedic measures. It is by no means a panacea and its limitations should be kept in mind. It may well be that the relief obtained is only of a temporary nature, and a review of the cases after a period of at least five years is essential before any final pronouncement is made on the lasting effects of gold therapy. Reports in the literature of follow-ups are conspicuous by their absence. Moreover, gold is a dangerous drug, and toxic reactions have been reported by some authorities in over $50 \%$ of their patients. For this reason I feel that gold salts should be given only by those who have had experience in their use and are fully aware of the dangers.

\section{Summary}

1. Of 103 cases of rheumatoid arthritis who were observed over a period of one year, 57 received injections of myocrisin and 46 an inactive control substance. At the time it was not known to the observer what each patient received.

2. Some clinical improvement was observed in $82 \%$ of the patients on myocrisin and in $45 \%$ of those on the control, but the degree of improvement was more marked in the former group.

3. In assessing any form of treatment it is essential that the investigation should be adequately controlled, especially from the psychological aspect.

4. Toxic reactions occurred in $75 \%$ of the patients who received myocrisin, but most of these were of a mild nature. There were no deaths in this series, and only two patients, with exfoliative dermatitis, gave rise to some degree of anxiety.

5. Gold salts are of value in the treatment of rheumatoid arthritis, particularly when used in conjunction with general, physiotherapeutic, and orthopaedic measures. On account of their toxicity they should only be employed by those with experience in their use.

I wish to thank the Empire Rheumatism Council for a Personal Grant extending over two years, and Messrs. May and Baker, Ltd., for presenting ample supplies of myocrisin and the inactive control substance.

\section{REFERENCES}

Bach, F. (1936). St. Bart's Hosp. J., 43, 206

Benedict, S. R. (1922). J. biol. Chem., 51, 187

- (1922). Ibid., 54, 233.

Buckley, C. W. (1934). Brit. med. J., 1, 469.

Cecil, R. L., Kammerer, W. H., and De Prume, F. J. (1942). Ann. intern. Med., 16, 811.

Copeman, W. S. C., and Tegner, W. (1937). Lancet, 1, 554.

Crawford, J. C. C. (1937). Ulster med. J., 6, 29.

Crawford, J. C. C. (1937). Ulster med. J.,

Dawson, M. H., Boots, R. H., and Tyson, T. L. (1941). Trans. Ass. Amer. Phys., 56, 330 .

Ellman, P., and Lawrence, J. S. (1935). Brit. med. J., 2, 622.

El, and Thorold, G. P. (1940). Ibid., 2, 314

Feldt, A. (1917). Berl. klin. Wschr., 54, 1111.

(1927). Klin. Wschr., 6, 1136

- (1930). Med. Welt., 4, 437.

Forestier, J. (1929). Bull. Soc. méd. Hóp. Paris, 45, 323.

- (1935). J. Lab. clin. Med., 20, 827.

Graham, J. W., and Fletcher, A. A. (1943), Canad. med. Ass. J., 49, 483.

Hartfall, S. J., and Garland, H. G. (1935). Lancet, 2, 8. (1936). Ibid., 1, 1459.

- - and Goldie, W.'(1937). Ibid., 2, 784 and 838.

$\overline{\text { Hedenius, }}$, and Goldie, W. (1926). Acta med. scand. Suppt. No. 16, 313.

Hedenius, I. (1926). Acta med. scand. Suppt. No.
Junker (1913). Munch. med. Wschr., 60, 1376.

Key, J. A., Rosenfeld, H., and Tjoflat, O. E. (1939). J. Bone Jt.

Koch, R. (1890). Disch. med. Wschr. 16, 756.

Landé, K. (1927). Munch. med. Wschr., 74, 1132.

Lewy, F. H., and Freund, R. (1926). Disch. med. Wschr., 52, 1857. McIntosh, J. F., Möller, E., and Van Slyke, D. D. (1928). J. clin.
Invest., 6, 427 and 467 .

Möllgaard, H. (1924). Chemotherapy of Tuberculosis. Kjobenhavn. Oren, H. (1936) quoted by Rosenberg, E. F. (1942). Pro. Mayo Clin.,

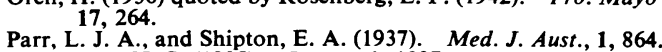

Parr, L. J. A., and Shipton, E. A. (1937).

Pemberton, H. S. (1935). Lancet, 1, 1037.
Philips, R. T. (1936). New Engl. J. Med., 214, 114.

Philips, R. T. (1936). New Engl. J. Med., 214,
Pick, E. (1927). Wien. klin. Wschr., 40, 1175.

Sashin, D., Spanbock, J., and Kling, D. H. (1939). J. Bone Jt. Surg., 21,723 .

Schmidt, L. (1944). Brit. med. J., 1, 433.

Secher, K., and Gudiksen, E. (1935). Acta med. scand., 86, 370.

Slot, G., and Deville, P. M. (1934). Lancet, 1, 73.

Snyder, R.G., Traeger, C., and Kelly, L. (1939). Ann. intern. Med., 12, 1672 .

Sundelin, F. (1941). Acta med. scand. Suppt., 117, 1.

Umber, F. (1929). Med. Welt., 3, 593 and 633.

Zimmer, A. (1930). Die Behandlung der rheumatischen Kraukheiten, Leipzig. 